\begin{tabular}{|lll|}
\hline Diterima & $:$ & 1 April 2020 \\
Direvisi & $:$ & 9 Juni 2020 \\
Disetujui & $:$ & 26 Juni 2020 \\
Diterbitkan & $:$ & 27 Juni 2020 \\
\hline
\end{tabular}

\title{
STRATEGI PEMBELAJARAN CHARACTER ACTIVITY CARD (CAC) SEBAGAI PENGEMBANGAN PERILAKU BERKARAKTER PESERTA DIDIK DI PAUD HAMPARAN BUNGA PASAMAN BARAT
}

\author{
Felayati ${ }^{1} \&$ Nenny Mahyuddin ${ }^{2}$ \\ email: felayati64@gmail.com ${ }^{1}$, nenny.mahyuddinpaud@gmail.com² \\ Pendidikan Guru PAUD Universitas Negeri Padang
}

Jalan Prof. Dr. Hamka, Air Tawar Baru, Kec. Padang Utara, Kota Padang, Sumatera Barat 25171

\begin{abstract}
Abstrak: Pendidikan karakter merupakan pembelajaran yang diutamakan dalam era Nawacita. Character Activity Card (CAC) adalah salah satu contoh strategi pembelajaran bagi anak usia dini bertujuan untuk menanamkan perilaku berkarakter. Dalam artikel ini penerapan CAC pada salah satu taman kanakkanak di Sumatera Barat dijadikan sebagai subjek penelitian. Penelitian ini adalah penelitian kualitatif yang menggunakan teknik deskriptif interpretif yang dilakukan untuk menggali dan menginterpretasikan informasi yang berhubungan erat dengan perilaku berkarakter yang dilakukan di Taman kanak-kanak Hamparan Bunga. Hasil penelitian menunjukkan bahwa pendidikan karakter dilakukan sejak anak mulai memasuki kelas setiap hari di Hamparan Bunga. Guru menanamkan nilai-nilai agama dan mengarahkan anak memilih bentuk perilaku karakter yang ada di CAC. Selanjutnya guru mengulang kembali perilaku karakter yang telah dilakukan anak, melalui sebuah cerita dalam tema pembelajaran inti di dalam kelas dan meminta anak mengulang dan menyebutkan perilaku berkarakter setelah selesai pembelajaran inti.
\end{abstract}

Kata-kata Kunci: character activity card (cac), perilaku berkarakter, strategi pembelajaran

\section{CHARACTER ACTIVITY CARD (CAC) LEARNING STRATEGY IN DEVELOPING CHARACTER BEHAVIOR OF CHILDREN IN HAMPARAN BUNGA KINDERGARTEN IN PASAMAN BARAT}

\begin{abstract}
Character education is one of the preferred learning in the Nawacita era. Character Activity Card $(C A C)$ is one example of learning strategies for early childhood aimed at instilling character behavior. In this article the application of CAC in one kindergarten in West Sumatra was made as a research subject. This research is a qualitative study using descriptive interpretive techniques that was carried out to explore and interpret information that is closely related to character behavior carried out in the Hamparan Bunga kindergarten. The results showed that character education was carried out since children began to enter the classroom every day. The teacher instills religious values and directs children to choose the forms of character behavior that exist in the CAC. Then the teacher repeats the character's behavior that the child has done, through a story in the core learning theme in the classroom and asks the child to repeat and mention the character's behavior after the completion of the main learning.
\end{abstract}

Keywords: character activity card (cac), character behavior, learning strategies 


\section{PENDAHULUAN}

Bangsa yang terbelakang, yang tidak jelas kemana arahnya, biasanya semakin banyak dipenuhi individu-individu, terutama pemimpinnya yang berkepribadian buruk seperti melakukan korupsi, manipulasi, dan perilaku negatif lainnya. Hal ini disebabkan oleh rusaknya kualitas kepribadian. Oleh sebab itu nilai-nilai berkarakter harus ditanamkan sejak usia dini. Sebagaimana menurut Muslich (2011) orang yang berkarakter (a person of character) ialah sesorang yang bertingkah laku sesuai dengan kaidah moral. Istilah karakter berkaitan dengan istilah kepribadian kepribadian, yang diartikan sebagai totalitas nilai yang mengarahkan manusia dalam menjalani hidupnya (Mu`in, 2011).

Karakter menjadi modal yang sangat penting untuk bersaing dan bekerja sama secara tangguh dan terhormat di tengah-tengah bangsa lain (ljudin, 2014). Karakterlah yang membuat bangsa Jepang cepat bangkit sesudah kekalahannya dalam Perang Dunia II dan meraih kembali martabatnya di dunia internasional. Karakterlah yang membuat bangsa Vietnam tidak bisa ditaklukkan, bahkan mengalahkan dua bangsa yang secara teknologi dan ekonomi yang lebih maju yaitu Prancis dan Amerika. Karakter menjadi benteng pertahanan suatu bangsa dan oleh karena itu pendidikan karakter menjadi sangat penting dikenalkan dan ditanamkan sejak usia dini di negara Indonesia.

Terutama pada pendidikan anak usia dini sangat perlu untuk memperhatikan dan menerapkan pendidikan karakter demi masa depan anak yang lebih baik. Menurut Santrock (2007) pendidikan karakter merupakan pendekatan langsung pada pendidikan moral, yakni mengajari murid dengan pengetahuan moral dasar untuk mencegah mereka melakukan tindakan tidak bermoral dan membahayakan orang lain dan dirinya sendiri.

Pendidikan anak usia dini merupakan pendidikan yang sangat fundamental dalam memberikan kerangka dasar terbentuk dan berkembangnya dasar-dasar pengetahuan, sikap dan keterampilan pada anak (Mardiani dkk, 2018). Menurut Yaswinda dkk (2018) pendidikan anak ketika usia dini merupakan dasar demi terbentuknya kepribadian seorang individu secara utuh, yakni dengan munculnya karakter, budi pekerti, kepandaian serta keterampilan. Dengan pendidikan karakter diharapkan pula anak-anak tumbuh paripurna atau sempurna.

Pada periode usia 0 - 6 tahun, otak anak sedang berkembang dengan sangat pesat (Sujiono \& Yuliani, 2009). Mereka akan mampu menyerap dengan cepat segala sesuatu yang dilihat atau didengarnya. Tahuntahun pertama kehidupan anak merupakan kurun waktu yang sangat penting dan kritis dalam hal tumbuh kembang fisik, mental, dan psiko sosial, yang berjalan sedemikian cepatnya sehingga keberhasilan tahuntahun pertama sebagian besar menentukan masa depan anak. Fadlillah \& Lilif (2013) menyebut masa kanak-kanak sebagai masa keemasan atau golden age dimana terjadi transformasi yang luar biasa pada otak dan fisik anak (Suryana \& Rizka, 2019). The golden age yaitu masa ketika anak mempunyai banyak potensi yang sangat baik untuk dikembangkan.

Usia dini merupakan usia yang sangat menentukan dalam membentuk kepribadian dan karekter anak (Sujono \& Yuliani, 2009). Lebih lanjut menurut Suryana (2013) nilai karakter perlu ditumbuhkembangkan melalui pendidikan, benihbenih individualitas yang sangat berharga itu yang memungkinkan terbentuknya suatu kepribadian unik akan tetap tinggal laten.

Membentuk karakter anak dilakukan dalam suatu proses pembentukan dan pembiasaan yang dilakukan berulang-ulang dan berkesinambungan. Pembentukan karakter pada anak adalah suatu usaha yang sungguh-sungguh, sistematik dan berkelanjutan untuk membangkitkan dan menguatkan kesadaran serta keyakinan anak terhadap bentukan perilaku yang menjadi ciri dan melekat serta menetap pada diri anak (Gularso \& Firoini, 2015). Namun, masih banyak guru taman kanak-kanak yang belum dapat memberikan pemahaman yang benar tentang pembentukan karakter pada anak. Penelitian yang dilakukan pada jenjang PAUD masih jarang. Emiasih melakukan penelitian pada jenjang SMA di Pekalongan (Emiasih, 2011). Hadiasi melakukan kajian pustaka mengenai pendididikan karakter pada PAUD (Hadiasi, 2015). Hasanah \& Deniatur (2018), Kusumandari (2013) dan Saptatiningsih \& Permana (2018) melakukan penelitian pada Pendidikan karakter di jenjang PAUD.

Masih terdapat guru taman kanak-kanak yang melakukan pembelajaran tanpa memahami tujuan yang harus dicapai dan dampaknya terhadap anak, khususnya tentang pendidikan karakter. Ketika proses pembelajaran guru hanya melaksanakan kegiatan inti, belum sampai pada kesadaran memaknai proses pembelajaran terhadap pembentukan karakter anak. Berdasarkan wawancara terhadap beberapa orang guru dari berbagai sekolah di Sumatera Barat didapatkan bahwa :

Pendidikan karakter yang sering diterapkan 
di sekolah ialah melalui buku cerita, berdasarkan tema kegiatan dan belum ada media ataupun model pembelajaran yang khusus untuk pendidikan karakter. Namun pendidikan karakter di taman kanak-kanak bersifat tersirat melalui tema-tema pembelajaran.

Karakter menurut Muslich (2011) berkaitan dengan kekuatan moral, berkonotasi "positif", bukan netral. Jadi orang berkarakter adalah orang yang memiliki kualitas moral (tertentu) positif. Sedangkan menurut Pusat Bahasa Depdiknas adalah bawaan, hati, jiwa, kepribadian, budi pekerti, perilaku, personalitas, sifat, tabiat, temperamen, watak. Adapun berkarakter adalah berkepribadian, berperilaku, bersifat, dan berwatak (Amri dkk, 2011).

Suyanto (2012) karakter diartikan sebagai nilainilai, sikap, dan perilaku yang dapat diterima oleh masyarakat luas, seperti etis, demokratis, hormat, bertanggung jawab, dapat dipercaya, adil, serta peduli, yang bersumber dari nilai-nilai kemasyarakatan, ideologi negara, dan kewarganegaraan, nilai-nilai budaya bangsa, agama, dan etnik yang diterima oleh masyarakat Indonesia secara luas sehingga tidak menimbulkan konlfik.

Individu yang memiliki karakter baik atau unggul akan berusaha melakukan hal-hal yang terbaik terhadap Tuhan YME, dirinya, sesama lingkungan, bangsa dan negara serta dunia Internasional pada umumnya dengan mengoptimalkan potensi pengetahuan dirinya disertai dengan kesadaran, emosi dan motovasinya. Menurut Simon Philips (Muslich, 2011) karakter adalah kumpulan tata nilai yang menuju pada suatu sistem, yang melandasi pemikiran, sikap dan perilaku yang ditampilkan.

Koesoema (2007) menyatakan bahwa karakter sama dengan kepribadian. Kepribadian dianggap sebagai "ciri atau karakteristik atau gaya atau sifat khas dari diri seseorang yang bersumber dari bentukan yang diterima dari lingkungan, misalnya keluarga pada masa kecil dan juga bawaan seseorang sejak lahir". Karakter berkaitan dengan kekuatan moral, berkonotasi "positif", bukan netral. Jadi orang berkarakter adalah orang yang memiliki kualitas moral (tertentu) positif.

Menurut Amri, dkk (2011) karakter merupakan pengaplikasian nilai kebaikan dalam bentuk tindakan atau tingkah laku sehingga perilakunya sesuai dengan kaidah moral yang disebut dengan karakter mulia, karakter mulia berarti individu yang memiliki nilai-nilai reflektif dan akhlak mulia seperti, jujur, mandiri, bertanggungjawab dan lain sebagainya. Koesoema (2007), menyatakan bahwa pendidikan karakter merupakan bagian dari kinerja sebuah lembaga pendidikan yang di dalamnya terdapat berbagai macam keterlibatan individu dan tata aturan kelembagaan.

Dengan demikian pendidikan adalah membangun karakter, yang secara implisit mengandung arti membangun sifat atau pola perilaku yang didasari atau berkaitan dengan dimensi moral yang positif atau yang baik, bukan yang negatif atau yang buruk (Muslich, 2011).

Merujuk pada definisi di atas, pendidikan karakter merupakan upaya penanaman nilai-nilai karakter kepada anak didik yang meliputi pengetahuan kesadaran atau kemampuan dan tindakan untuk melaksanakan nilai-nilai kebaikan dan kebijakan kepada Tuhan YME, diri sendiri, sesama, lingkungan maupun kebangsaan agar menjadi manusia yang berakhlak dan berbudi pekerti.

Dalam mewujudkan pendidikan karakter, tidak dapat dilakukan tanpa penanaman nilai-nilai (Azra, 2002). Terdapat sembilan pilar karakter yang berasal dari nilai-nilai luhur universal, yaitu:

1. Karakter cinta tuhan dan segenap ciptaan-Nya

2. Kemandirian dan tanggung jawab

3. Kejujuran dan amanah, diplomatis

4. Hormat dan santun

5. Dermawan, suka tolong-menolong, gotong royong/kerjasama

6. Percaya diri dan pekerja keras

7. Kepemimpinan dan keadilan

8. Baik dan rendah hati

9. Karakter toleransi, kedamaian, dan kesatuan

Keberhasilan pembentukan karakter pada anak sangat tergantung pada komitmen sekolah dan guru dalam mengembangkan visi sekolah untuk membentuk karakter. Untuk itu pada pembelajaran pendidikan anak usia dini diperlukan strategi pembelajaran inovatif. Sudah menjadi keharusan bahwa dalam menyajikan suatu pembelajaran dibutuhkan suatu strategi pembelajaran yang mudah dan bisa dinikmati oleh anak didik apalagi dalam pembelajaran anak usia dini. Pembelajaran yang bermakna yang disajikan oleh guru untuk anak usia dini akan berdampak signifikan pada perkembangan anak.

Strategi merupakan usaha untuk memperoleh kesuksesan dan keberhasilan dalam mencapai tujuan. Dalam dunia pendidikan strategi dapat diartikan sebagai a plan, method, or series of activities designed to achieve a particular educational goal (David, 1976 dalam Santrock, 2007). Strategi pembelajaran dapat diartikan sebagai perencanaan yang berisi tentang rangkaian kegiatan yang didesain untuk mencapai tujuan pendidikan tertentu.

Strategi pembelajaran adalah suatu kegiatan 
pembelajaran yang harus dikerjakan guru dan siswa agar tujuan pembelajaran dapat dicapai secara efektif dan efisien (Kemp, 1995 dalam Santrock, 2007). Dapat disimpulkan bahwa strategi pembelajaran adalah suatu set materi dan prosedur pembelajaran yang digunakan secara bersama-sama untuk menimbulkan hasil belajar pada siswa.

Strategi pembelajaran CAC (Character Activity Card) merupakan metode pembelajaran karakter yang divariasikan dengan menggunakan kartu bergambar. Nilai-nilai karakter yang terdapat did alam kartu bergambar dapat dipilih oleh anak sesuai dengan minat anak, kemudian anak melakukan kegiatan berkarakter sesuai dengan kartu bergambar yang telah dipilih. Strategi pembelajaran kreatif dinilai mampu memberikan kesan pada murid. Hal ini sejalan dengan penelitian yang dilakukan oleh ljudin (2014) ialah strategi yang tidak hanya menitikberatkan pada perkembangan kognitif, tetapi juga afektif pada diri peserta didik. Perbedaan dengan penelitian ini ialah bahwa strategi pendidikan karakter yang dirancang berupa pembelajaran Character Activity Card (CAC). Inovasi pembelajaran yang di terapkan dalam penelitin ini adalah model pembelajaran Character Activity Card yang merupakan strategi pembelajaran yang menarik, kreatif, dan berbentuk permainan edukatif.

\section{METODE PENELITIAN}

Penelitian ini adalah penelitian kualitatif dengan teknik yang digunakan adalah deskriptif interpretivis (Sugiyono, 2012). Subjek penelitian adalah program pembiasaan pembelajaran CAC yang diberikan kepada murid taman kanak-kanak di sebuah kota di Sumatera Barat yang berjumlah 20 orang yang dilakukan oleh guru. Data yang dikumpulkan adalah data primer dan data sekunder. Data primer dalam penelitian ini berupa aktivitas pembiasaan yang dilakukan murid yang difasilitasi oleh guru yang diperoleh melalui pengamatan langsung (observasi), sedangkan data sekunder berupa wawancara dengan murid, guru dan orangtua murid. Analisis data menggunakan deskriptif interpretatif.

\section{HASIL DAN PEMBAHASAN}

Hasil penelitian menunjukkan bahwa CAC dilakukan oleh anak pada waktu pagi hari saat anak memasuki sekolah dengan dipandu guru. Tujuan dari pembelajaran CAC adalah untuk penanaman nilai karakter sesuai dengan minat anak. Pembelajaran CAC yang dilakukan pada setiap proses pembelajaran di setiap harinya akan menjadikan sebuah kebiasaan yang tertanam pada diri anak. Pembiasaan yang dilakukan terdiri atas 6 kegiatan yaitu kegiatan rutin, kegiatan spontan, kegiatan teladan, kegiatan terprogram, kegiatan nasionalisme, dan kegiatan outbond learning and training. Saat penerapan CAC ini dapat dilakukan change atau perubahan giliran apabila anak tidak tertarik dengan nilai-nilai karakter lainnya. Berdasarkan hasil pengamatan ketika guru melakukan sebuah inovasi pada sebuah pembelajaran anak terlihat antusias dan penasaran untuk mengikuti proses pembelajaran.

Hasil pengamatan ini didukung oleh pernyataan salah satu guru yang mengajarkan pendidikan karakter di taman kanak-kanak ini yang mengatakan bahwa: anak-anak cenderung bersemangat dan penasaran pada setiap gambar yang diperlihatkan oleh guru kepada mereka dan mereka akan selalu berebutan untuk memilih kartu giliran pertama.

Para guru bertugas memberikan contoh dan arahan kepada murid dengan kartu bergambar karakter sebagai media. Selain kartu bergambar yang telah disediakan, guru berperan untuk memberikan contoh dalam proses pembelajaran. Seperti (1) mengucap salam ketika bertemu, menjawab salam, dan menjabat tangan, saat bertemu dan akan berpisah dengan anak atau orang tua; (2) berdoa sebelum dan sesudah kegiatan; (3) menjaga kebersihan; (4) bertanggung jawab; (5) mensyukuri berkah Tuhan dengan menghabiskan makanan ringan dan makan siang yang tersedia; (6) berkomunikasi positif dengan sikap hormat dan bahasa yang santun kepada orang lain; (7) menjawab pertanyaan anak dan mendengarkan anak berbicara; (8) bersabar menunggu giliran (9) hemat (10) tampil penuh percaya diri; (11) sikap kepemimpinan, (12) menghargai anak dan memberikan; (13) bersikap empati; (14) konsisten pada peraturan dan (15) rajin beribadah.

Model pembelajaran yang dilakukan di sekolah ini adalah sebagai berikut: pada kegiatan awal memasuki sekolah kita bisa melihat sikap hormat anak kepada guru dengan mencium tangan guru dan orang tua, serta kecintaan terhadap Tuhan Yang Maha Esa telah ditanamkan oleh orang tua dan guru seperti mengucapkan salam, kemudian guru menyambut anak dengan sambutan yang menyenangkan di pagi 
hari seperti bertepuk tangan, pelukan dan usapan kepala dan secara teratur anak meletakkan tas ke dalam kelas.

Selanjutnya anak diminta untuk memilih satu kartu karakter dengan menancapkan tangan pada pilihan kartu, guru mendampingi anak dan menjelaskan kartu karakter bergambar. Setiap pagi anak akan memilih salah satu kartu karakter, anak diarahkan untuk memilih kartu karakter yang berbeda pada hari berikutnya. Anak terlihat antusias saat memilih dan melakukan kegiatan CAC atau kartu kegiatan karakter. Setelah anak melakukan CAC atau kegiatan kartu karakter, anak dipersilahkan untuk bermain bersama teman.

Pada kegiatan inti ini juga anak menerapkan perilaku berkarakter seperti membaca bissmilahirahmanirrahim sebelum belajar. Guru membuka pembelajaran inti dengan menanyakan kembali aktivitas CAC yang telah dilakukan dan guru menghubungkan dengan tema pembelajaran dan menjelaskan perilaku karakter yang ada pada kegiatan CAC. Guru bercerita dan bertanya jawab siapa yang menciptakan kita, siapa yang melakukan kegiatan CAC yang berhubungan dengan mengingat Allah, seperti ibadah, sedekah, sholat Dhuha, berdzikir dan menyanyikan asmaul husna.

Selanjutnya guru menjelaskan tentang tema pembelajaran pada hari itu dan menghubungkan dengan perilaku karakter yang ada pada CAC agar anak dapat memahami setiap kegiatan CAC yang dilakukan. Pemahaman tentang berbagai perilaku baik selalu disampaikan guru saat memasuki tema pembelajaran, seperti tema lingkunganku. Pada tema ini guru menceritakan kepada anak bahwa lingkungan kita harus dijaga dengan baik, menjaga lingkungan kita dengan adanya kegiatan bergotong royong atau tolong menolong untuk bersama-sama menjaga kebersihan lingkungan. Tema lainnya seperti diriku, guru menjelaskan tentang hasil ciptaan tuhan, mandiri merawat diri atau tubuh dan lain sebagainya.

Pada kegiatan akhir proses pembelajaran ditutup dengan memberikan apresiasi kepada anak yang artinya mulai dari merangkum kegiatan pada hari ini dan merangkum kegiatan CAC dan perilaku berkarakter yang harus senantiasa menjadi kebiasaan kita. Guru menstimulasi anak untuk mengulang kembali bentuk-bentuk perilaku karakter yang ada dalam tema pembelajaran yang telah dilakukan dan anak antusias untuk menyebutkan perilaku berkarakter. Guru juga selalu memberikan reward atau pujian terhadap perilaku berkarakter yang disebutkan oleh anak.

Dari paparan di atas guru memberikan pemahaman dan penanaman nilai-nilai karakter, kemudian mencontohkan dan selalu mengingatkan anak tentang perilaku berkarakter yang senantiasa harus dimiliki oleh setiap individu. Dalam uraian di atas menggambarkan peranan guru dalam pengembangan pendidikan karakter di sekolah yang berkedudukan sebagai katalisator atau teladan, inspirator, motivator, dinamisator, dan evaluator. Dalam berperan sebagai katalisator, maka keteladanan seorang guru merupakan faktor mutlak dalam pengembangan pendidikan karakter peserta didik yang efektif, karena kedudukannya sebagai figur atau idola yang digugu dan ditiru oleh peserta didik (ljudin,2014).

Sutrisno (2005:17) yang mengatakan bahwa guru yang baik dapat memanfaatkan pelbagai situasi yang dihadapinya untuk membelajarkan anak yang beraneka kemampuan dan latar belakang. Sebagai sebuah pembelajaran klasikal tentulah pembelajaran itu harus menyentuh seluruh anak yang ada di kelas dan di taman kanak-kanak. Guru dituntut untuk memberikan pengawasan dan perhatian yang sama kepada semua anak, sehingga perilaku berkarakter tidak hanya ditampilkan sebagian anak saja

\section{PENUTUP}

\section{Kesimpulan}

Berdasarkan hasil penelitian dan pembahasan dapat dikemukakan beberapa hal berkaitan dengan karakter anak dalam pembelajaran CAC di Taman Kanak-kanak Hamparan Bunga yaitu guru membelajarkan anak perilaku berkarakter yang di mulai dengan nilai-nilai agama, hormat dan santun, disiplin, mandiri, bertanggung jawab, dan tolong menolong. Perilaku berkarakter telah dilakukan dan mulai dijadikan pembiasaan dalam lingkungan Taman Kanak-kanak Hamparan Bunga.

\section{Saran}

Tenaga pendidik taman kanak-kanak agar dapat menambahkan kreativitas dan model tampilan media bergambar karakter pada anak. Baik secara manual, digital dan lain sebagainya.

Peneliti selanjutnya agar dapat menggunakan metode penelitian yang dapat menggali secara mendalam tentang keefektifan media begambar karakter sebagai penananam nilai-nilai karakter untuk anak usia dini. 


\section{DAFTAR PUSTAKA}

Amri, S., Jauhari, A., \& Tatik, E. (2011). Implementasi Pendidikan Karakter dalam Pembelajaran: Strategi, Analisis dan Pengembangan Karakter Siswa dalam Proses Pembelajaran. Jakarta: PT. Prestasi Pustakaraya.

Azra, A. (2002). Paradigma Baru Pendidikan Nasional: Rekonstruksi dan Demokratisasi. Jakarta: Kompas.

Emiasih, D. (2011). Pengaruh Pemahaman Guru tentang Pendidikan Karakter terhadap Pelaksanaan Pendidikan Karakter pada Mata Pelajaran Sosiologi. Jurnal Komunitas, 3 (2), 216-226. DOI: 10.15294/komunitas.v3i2.2318

Fadlillah, M \& Lilif, M. K. (2013). Pendidikan Karakter anak usiadini. Yogyakarta: Ar-Ruzz Media.

Gularso. D., \& Firoini, KA. (2015). Pendidikan Karakter melalui Program Pembiasaan di SD Islam Terpadu Insan Utama Bantul Yogyakarta. Trihayu: Jurnal Pendidikan Ke-SD-an, 1 (3), 19-25. DOI: 10.30738/trihayu.v2i2.732.g1438

Hadiasi, La. (2015). Pendidikan Karakter pada Anak Usia Dini. Jurnal Al-Ta'dib, 8 (2), 50-69. Diakses melalui https://media.neliti.com/media/ publications/235796-pendidikan-karakter-padaanak-usia-dini-9a0f6ea6.pdf

Hasanah, U \& Deniatur, M. (2018). Earlychilhood Research Journal, 1 (1), 50-62. DOI: 10.23917/ ecrj.v1i1.6578

ljudin,. (2014). Strategi pengembangan mutu lembaga pendidikan melalui pendidikan karakter. Jurnal Pendidikan UNIGA. 8 (1), 86-115. Diakses melalui https://journal.uniga.ac.id/ index.php/JP/article/view/72

Koesoema A, D. (2007). Pendidikan karakter: Strategi mendidik anak di zaman modren. Jakarta: P T. Grasindo.

Kusumandari, RA. (2013). Character Education Model for Early Childhood based on E-Learning and Culture of Java. Indonesian Journal of Early Childhood Education Studies, 2 (1), 20-28. Diakses melalui http://journal.unnes.ac.id/sju/ index.php/ijeces

Mardiani, T., Zulmiati., \& Mahyuddin, N. (2018).
Hubungan bimbingan guru terhadap kemandirian anak di taman kanak-kanak gugus bougenville 1 kecamatan Koto Tangan Padang. Jurnal Bunga Rampai Usia Emas. 4 (2), 18-23. Diakses melalui https://jurnal.unimed.ac.id/2012/index. php/jhp/article/view/12116/10514

Mu`in, F. (2011). Pendidikan karakter: Konstruksi teoritik \& praktik (Urgensi pendidikan progresif dan revitalisasi peran guru dan orangtua). Jogjakarta: ArRuzz Media.

Muslich, M. (2011). Pendidikan Karakter: Menjawab Tantangan Krisis Multidimensional. Jakarta: Bumi Aksara.

Santrock, J.W. (2007). Adolescence, edisi keenam (Adelar, S.B \& Sherly, Penerjemah). Jakarta: Erlangga.

Saptatiningsih, RI; \& Permana, SA. (2019). Early Childhood Character Building Throuhtechnological Education. Journal of Physics: Conference Series, $1^{\text {st }}$ UPY International Conference on Applied Science and Education, 1-8. DOI: 10.1088/1742-6596/1254/1/012048

Sugiyono. (2012). Metode Penelitian Pendidikan: Pendekatan Kuantitatif, Kualitatif dan R\&D. Bandung: Alfabeta.

Sujiono, Yuliani N. (2009). Konsep Dasar Pendidikan Anak Usia Dini. Jakarta: PT Indeks

Suryana, D. (2013). Pendidikan Anak Usia Dini: Teori dan Praktik Pembelajaran. Padang: UNP Press Padang.

Suryana, D., \& Rizka, N. (2019). Manajemen Pendidikan Anak Usia Dini Berbasis Akreditasi Lembaga. Jakarta: Prenadamedia Group.

Suyanto. S.( 2012). Pendidikan karakter untuk anak usia dini. Jurnal Pendidikan Anak 1, (1), 1-10. DOI: 10.21831/jpa.v1i1.2898

Yaswinda, Yulsyofriend, Mayar. F. (2018). Pengembangan bahan pembelajaran sains berbasis multisensori Ekologi Bagi Guru Paud Kecamatan Tilatang Kamang Kabupaten Agam. Yaa Bunayya: Jurnal Pendidikan Anak Usia Dini, 2 (2), 13-22. Diakses melalui https://jurnal.umj. ac.id/index.php/YaaBunayya/article/view/3744. 